\title{
Aliados incómodos. Tradiciones obreras y sindicales en Rosario a principios de los años sesenta
}

\section{Uncomfortable allies. Worker and union traditions in Rosario at the beginning of the sixties}

\author{
Silvia Simonassi* \\ Verónica Vogelmann ${ }^{* * *}$
}

\begin{abstract}
Resumen: El objetivo de este artículo es analizar las tradiciones obreras y sindicales que se articularon en Rosario, Argentina, a principios de los años sesenta. Para ello, indagamos en las diferentes vertientes sindicales que se movieron en el escenario nacional y local, a saber: el peronismo tradicional, el activismo comunista y una nueva camada de militantes gremiales que se destacaron en los procesos de conflictividad de fines de los años cincuenta en el sector estatal y que hegemonizaron la directiva de la CGT Regional Rosario a partir del año 1963. Exploramos las relaciones tramadas entre estos grupos, las cuales oscilaron entre los esfuerzos de unidad ante los embates patronales y estatales y las disputas, luchas $\mathrm{y}$ fricciones que los dividieron $\mathrm{y}$ enfrentaron.
\end{abstract}

Palabras clave: Tradiciones, clase obrera, organización sindical, Rosario

\begin{abstract}
The aim of this article is to analize the working-class and trade-union traditions that articulated in Rosario, Argentina, at the beginning of the sixties. In order to do so, we inquired into the different union branches that acted in the national and local scene, namely: traditional peronism, comunist activism and a new generation of trade-union activists who stood out in the conflict processes at the end of the fifties in the state sector, and who hegemonized the leadership of the Confederación General del Trabajo from 1963. We explore the relations weaved between them, which oscillated among the efforts towards unity in the face of the trade-asociation and state
\end{abstract}

\footnotetext{
* Este trabajo forma parte del Proyecto de Investigación y Desarrollo "Empresarios, trabajadores y comunidades urbanas en Argentina durante el siglo XX”, Dir. Dra. Silvia Simonassi, HUM 443, Res. CS. 110/2014, UNR, y del Proyecto Posdoctoral de CONICET "Los trabajadores de la carne en Rosario y su región: organización gremial, participación política y conflictividad social, 1943-1960”, Res. 1838, 20142016.

${ }^{* *}$ Co-autora. Argentina, ISHIR-CESOR/UNR, silviags@express.com.ar

${ }^{* * *}$ Co-autora. Argentina, CONICET-NET/UNR, veronicavogelmann@gmail.com
} 
assaults and the disputes, fights and frictions that divided them and made them confront.

Keywords: traditions, working class, union organization, Rosario

Recibido: 24 diciembre 2016

Aceptado: 9 marzo 2017

\section{Introducción}

La historiografía sobre la experiencia obrera, la conflictividad laboral y las relaciones tramadas entre obreros y patrones durante los años sesenta en América Latina, ha subrayado la relevancia del proceso de protesta, movilización y radicalización política potenciado tras la Revolución Cubana y que caracterizó la "larga" década del sesenta en el conjunto del subcontinente. Esa misma producción ha hurgado en las ostensibles heterogeneidades regionales de esos procesos más generales, que obedecieron a estructuras productivas, tradiciones sindicales y políticas e historias empresarias diversas.

En tal sentido, la historiografía obrera sobre los trabajadores en el Gran Rosario - una de las áreas industriales más relevantes de Argentina-, se ha concentrado en las experiencias de radicalización y movilización de fines de los sesenta y principios de los setenta. ${ }^{1}$ Menos se

${ }^{1}$ Beba Balvé y Beatriz Balvé, El '69. Huelga política de masas. Rosariazo, cordobazo, rosariazo, Buenos Aires, Editorial Contrapunto, 1989; José Pérez y Cristina Viano, "El 69: del mayo rosarino al Rosariazo", en Patricia Berrotarán y Pablo Pozzi (comp.), Estudios inconformistas sobre la clase obrera argentina, 19551989, Buenos Aires, Letra Buena, 1994; Gabriela Aguila y Cristina Viano, “Trabajador@s y militantes: sobre algunas vertientes de la izquierda peronista del norte al sur del cordón industrial del Gran Rosario entre 1969 y 1976. Una aproximación desde la historia oral”, Anuario de la Escuela de Historia 19, Rosario, 2002; Leónidas Ceruti y Mariano Resels, Democracia directa y gestión obrera. El SOEPU, la intersindical de San Lorenzo y la coordinadora de gremios. 1962-1976, Rosario, Ediciones del Castillo, 2006; Débora Cerio, "Revisando los relatos sobre una experiencia de organización obrera: el Sindicato de Obreros y Empleados Petroquímicos Unidos en los años '70", en Taller. Revista de Sociedad, Cultura y Política 24, 2007; Silvia Simonassi, "Conflictividad laboral y políticas disciplinarias en la industria metalúrgica de la ciudad de Rosario 1973-1976", Anuario IEHS 22, Tandil, 2007; Verónica Vogelmann, "Los trabajadores de la carne en el Gran Rosario. Organización gremial y conflictividad laboral (1969-1976)", Historia Regional 31, Villa Constitución, 2013; Laura Scopetta y Pablo Torres, "La apuesta armada. Notas sobre la política sindical del PRT-ERP en el Gran Rosario (1965-1976), seminario regional, inédito, 2014; Andrés Carminati, "Elementos extraños con brazaletes rojos". Radicalización obrera y lucha armada en una metalúrgica mediana de la ciudad de Rosario (1973-1976)" en Alejandra Ciriza, Fabiana Graselli y Laura Rodríguez Agüero (comp.) La centralidad de la política en los 70. Lecturas sobre un tiempo disruptivo, Mendoza, EDIUNC (en prensa), entre otros. Un estado de la cuestión más exhaustivo hemos presentado en: Silvia Simonassi, "La conflictividad obrera en el Gran Rosario durante la década de 1960: rediscusión de las principales hipótesis y 
ha indagado sobre el comportamiento obrero y sindical en los tempranos sesenta ${ }^{2}$, por lo cual las interpretaciones circulantes sobre el tema, provienen de un conjunto de memorias escritas - publicadas o inéditas- por los actores de estos procesos. ${ }^{3}$ En buena parte de esa producción se enfatizan las tradiciones combativas y antiburocráticas del sindicalismo local, fuertemente asociadas al citado contexto de radicalización que tuvo en Rosario su expresión en los dos "Rosariazos" de mayo y setiembre de 1969. Los principales portadores de esas memorias fueron quienes hegemonizaron la conducción de la Confederación General del Trabajo (CGT) Regional Rosario desde agosto de 1963 hasta fines de la década. Se trataba de una nueva camada de militantes con contornos definidos, provenientes de la Asociación de Trabajadores del Estado (ATE) Regional Rosario, predominantemente peronistas y partícipes de la "Resistencia". Es el caso de Héctor Quagliaro y Mario Aguirre.

En efecto, en Argentina a mediados de la década de 1950 y principios de la siguiente se fueron conformando nuevas tradiciones gremiales, al calor de la resistencia obrera a la "Revolución Libertadora", de las luchas contra los procesos de racionalización productiva y del extendido movimiento de tomas de fábrica de los años 1962-1964. Sin embargo, es preciso no exagerar la novedad, pues esas tradiciones se articularon con otras preexistentes, para finalmente confluir en el citado proceso de radicalización de las luchas sociales de fines de los sesenta y principios de los setenta. En el caso rosarino, diferentes fracciones del peronismo y un dinámico activismo comunista nutrieron la militancia obrera y sindical local mucho antes de la "irrupción" de la citada nueva camada de militantes gremiales. En efecto, esta última no puede ser pensada sin la actuación de la denominada "generación de los '40” comunista y el peronismo sindical de viejo cuño.

De modo que el objetivo principal de este artículo es indagar en esas diferentes tradiciones obreras y sindicales, que confluyeron en el escenario social y laboral de principios de la

propuesta de investigación”, ponencia XV Jornadas Interescuelas Departamentos de Historia, Comodoro Rivadavia, 2015.

${ }^{2}$ Paulo Menotti, “Al sur, un faro de luces y sombras. Historias de militancia, trabajo y explotación en el Swift. La experiencia de los comunistas", tesis de licenciatura UNR, inédita, 2008; Verónica Vogelmann, "Conflictividad laboral en épocas de 'resistencia'. Los trabajadores de los frigoríficos rosarinos tras el Golpe de Estado de 1955”, ponencia VIII de Sociología de la UNLP, La Plata, 2014; Silvia Simonassi y Verónica Vogelmann, "Tradiciones gremiales, conflictividad y organización obrera en Rosario durante la década del sesenta", ponencia IV Workshop Trabajadores, empresarios y comunidades obreras: conceptos, problemas y escalas de análisis, Rosario, 2016.

${ }^{3}$ AAVV, Nosotros la Resistencia, Rosario, Junta Promotora de Estudios Históricos y Políticos Martín Fierro, 1998; Hugo Ojeda, Quagliaro. La vida de un rosarino en la historia del movimiento obrero, Rosario, Ediciones ATE-Rosario, 2006; Mario Aguirre, Mario “Negro” Aguirre. Autobiografía. Por el camino de la emancipación, Rosario, Germinal Ediciones, 2009; Amor Hernández, Con la marca en el orillo. La memoria de los héroes que no tienen monumento, Rosario, Ediciones del autor, 2015 y Jaskel Shapiro, Asalto a la democracia sindical, Rosario, Ediciones Cuaderno, 2015. Entre las inéditas: Oscar González, Anécdotas, 1957 a 1969 y Biografía, 12 de mayo de 1983, Villa Gobernador Gálvez; entre otras que se citan en el cuerpo del texto. 
década del sesenta en la ciudad de Rosario, deteniéndonos en el análisis del proceso de conformación y consolidación de esa nueva camada de activistas, en tanto constituye una tradición gremial diferente, la cual no es posible comprender sin ahondar en las tradiciones preexistentes y sus complejas relaciones.

Es preciso señalar que el concepto de tradiciones ha sido una herramienta teórica sumamente rica para explorar los sentidos, valores y comportamientos de los conjuntos sociales en tanto fuerza activa y configurativa de las prácticas y significaciones de los sujetos históricos. Distintos autores han contribuido a otorgar dinamismo y énfasis explicativo a dicha noción distanciándose de aquellas perspectivas que la concibe como tiempo histórico inerte y supervivencia del pasado. ${ }^{4}$ Retomando estos aportes, en el presente artículo se considera a las tradiciones obreras y sindicales como procesos activos que articulan y legitiman los sentidos, valores y prácticas de colectivos de trabajadores particulares. Las tradiciones gremiales remiten a una herencia de situaciones anteriores y sus legados, a experiencias comunes duraderas que configuran distintas expresiones o estrategias políticas. ${ }^{5}$

Dichas tradiciones están inscriptas en relaciones materiales de explotación y, junto con los procesos de trabajo y la acción gubernamental frente a las reivindicaciones y organizaciones obreras, representan una dimensión fundamental y son expresión de la cultura de la clase trabajadora. ${ }^{6}$ Las tradiciones obreras y sindicales constituyen el resultado del accionar de diferentes corrientes políticas que disputan en el interior del mundo sindical $^{7}$ como así también de los sentidos, valores y prácticas desarrollados por los trabajadores en sus espacios de relaciones cotidianos, en sus luchas y negociaciones. De modo que, algunos momentos claves de la conflictividad y de los procesos de organización gremial se erigen como coyunturas críticas al establecer características que tienden a reproducirse en legados que forman parte de las tradiciones sindicales. ${ }^{8}$

\footnotetext{
${ }^{4}$ Raymond Williams, Marxismo y Literatura, Barcelona, Península, 1980, 137-142; Edward Palmer Thompson, La Formación de la Clase Obrera en Inglaterra, Barcelona, Crítica, 1989; Eric Hobsbawm, "Introducción" y "La fabricación en serie de tradiciones: Europa, 1870- 1914", en La invención de la tradición, Barcelona, Crítica, 2002, 7-21 y 273-318.

${ }^{5}$ Mariela Cambiasso y Julieta Longo "La noción de experiencia en E. P. Thompson: una propuesta para el análisis de los casos de alimentación y comercio en la posconvertibilidad”, Revista Rey Desnudo 3: II, 2013, 9 .

${ }^{6}$ Victoria Novelo, "La cultura obrera, una contrapropuesta cultural”, Nueva Antropología, 232: VI, México, marzo de 1984, 45-56.

${ }^{7}$ José Ricardo Ramalho y Marco Aurélio Santana, "Tradição sindical e as mudanças econômicas dos anos de 1990. O caso dos metalúrgicos do Rio de Janeiro", Trabalho e tradição sindical no Rio de Janeiro. A Trajetória dos metalúrgicos, Rio de Janeiro, DP\&A editora - FAPERJ, 2001, 19-20.

${ }^{8}$ Julián Gindin, "La tradición sindical y la explicación de las prácticas sindicales. Conclusiones de una comparación internacional sobre los docentes del sector público", Revista Latinoamericana de Estudos do Trabalho, 16: 26, 2011, 121.
} 
Para el abordaje de los objetivos planteados, apelamos a un conjunto diverso de fuentes: prensa periódica local y provincial, materiales de las corrientes políticas que participaron en la escena sindical local, documentos disponibles en archivos privados, memorias escritas y entrevistas orales.

Se presentan en primer lugar, algunos rasgos fundamentales del contexto socioeconómico y sindical nacional. En segundo término, se indaga en la reconfiguración de las tradiciones sindicales locales a partir de la caída del gobierno peronista en 1955, enfatizando en algunas fracciones del peronismo local y en el activismo sindical comunista. En tercer lugar, se explora el proceso de encumbramiento y consolidación sindical del grupo de ATE Rosario, como modo de abordar la conformación de una nueva tradición gremial. En cuarto lugar, se profundiza en el análisis del proceso de pocos meses que va desde la victoria de la lista unitaria para la conducción de la CGT Regional Rosario hasta el estallido de dramáticos episodios que enfrentaron a las distintas corrientes, a los fines de mostrar como se entrelazaron las distintas tradiciones sindicales. Finalmente, se presenta un conjunto de conclusiones.

\section{Economía y política en la lucha y organización obrera y sindical en Argentina}

Tras el derrocamiento del gobierno peronista en el mes de setiembre de 1955, se pusieron en debate los fundamentos de su política económica, en el controversial marco de una rediscusión de las alianzas sociales y políticas que lo habían sostenido. La idea de "desperonización" sustentada por sus antiguos adversarios, tanto civiles como militares, suponía desmantelar la herencia peronista transformando la matriz económica de la Argentina. Esto significó para la clase trabajadora un ataque a sus conquistas históricas mediante cambios en la legislación y en los convenios colectivos de trabajo, intervenciones de las organizaciones gremiales, cárcel y persecución de activistas. En respuesta, los trabajadores desarrollaron masivas acciones de repudio que representaron la base de la denominada "Resistencia" y consistieron en alzamientos cívicos militares, huelgas, sabotajes industriales, manifestaciones en barrios obreros y conflictos cotidianos en los lugares de trabajo. ${ }^{9}$ A partir de entonces se proscribió al peronismo, lo cual se expresó en la prohibición de cualquiera de sus manifestaciones, tanto materiales como simbólicas. ${ }^{10}$

En el plano sindical y sobre este contexto represivo, fue surgiendo un nuevo liderazgo, desde fines de 1956 se fue desarrollando un proceso de normalización restringida de las organizaciones gremiales y comisiones internas y hacia mediados de 1957 antiguos

\footnotetext{
${ }^{9}$ Alejandro Schneider, Compañeros. Trabajadores, izquierda y peronismo en la Argentina, 1950-1973, Buenos Aires, Imago Mundi, 2005, 97-103.

${ }^{10}$ Ernesto Salas, La resistencia peronista. La toma del Frigorífico Lisandro de la Torre, Buenos Aires, Retórica Ediciones, Altamira, 2006, 54 y 82-88.
} 
dirigentes conformaron la CGT Auténtica a cargo de Andrés Framini, referente peronista y dirigente de los textiles, quien mantuvo una posición intransigente contra el gobierno de facto. A principios de ese mismo año fue creado un agrupamiento sindical unitario, la Comisión Intersindical. Impulsado inicialmente por los comunistas fue controlado, sobre mediados de ese año, por sectores del peronismo. Desde allí promovieron las elecciones libres en todos los sindicatos, la recuperación de la CGT y la libertad de los presos por cuestiones gremiales. Durante algunos meses la Intersindical llevó adelante medidas de fuerza de carácter general que contaron con un amplio acatamiento. ${ }^{11}$ Mientras tanto, cada vez más organizaciones sindicales se fueron normalizando, al tiempo que se revitalizaban distintas comisiones internas.

En agosto de 1957 surgió el agrupamiento sindical más significativo de toda esta etapa: las 62 Organizaciones, la cual en sus orígenes reflejó la acción unitaria de los sectores comunistas y peronistas en el movimiento obrero. Su aparición se dio en el marco del Congreso Normalizador de la CGT nacional que tenía por objetivo adoptar nuevos estatutos y dar por finalizada la intervención. El mismo no pudo llevarse a cabo y derivó en una división que caracterizó durante años al movimiento obrero argentino: los 32 Gremios Democráticos y Mayoritarios y las 62 Organizaciones. ${ }^{12}$

Con la CGT intervenida, la conformación de las 62 Organizaciones constituyó un fenómeno de relevancia en tanto se fue transformando en la dirección centralizada del movimiento obrero para enfrentar al régimen militar. Además de la coordinación de paros generales, en sus primeros meses de actuación fue parte fundamental de la elaboración del programa político y de lucha, conocido como 'Programa de La Falda' donde se expresaron posiciones clasistas que proponían, entre otro conjunto de medidas, el control obrero de la producción y la participación efectiva de los trabajadores en la elaboración y ejecución del plan económico general y en la dirección de las empresas privadas y públicas. ${ }^{13}$

La unidad entre comunistas y peronistas comenzó a debilitarse en el marco de los acuerdos y pactos entre Frondizi ${ }^{14}$ y Perón para las elecciones nacionales. Allí se negoció la promulgación de una Ley Asociaciones Profesionales que no sólo normalizaría el

\footnotetext{
${ }^{11}$ En abril de 1957 la Intersindical incluía a treinta y cinco sindicatos y cinco federaciones, luego se fueron incorporando gremios grandes como textiles, metalúrgicos y carne, acrecentando la influencia peronista. Véase Daniel James, Resistencia e integración. El peronismo y la clase trabajadora argentina, 1946-1976, Buenos Aires, Siglo XXI, 2005,109-110; Schneider, op. cit., 103-106.

${ }^{12}$ Los 32 Gremios democráticos agrupó a gráficos, bancarios, seccionales de la Unión Ferroviaria, comercio, vestido, municipales y otros gremios dirigidos por socialistas y antiperonistas, véase James, Ibid., 111. En las 62 Organizaciones confluyeron: metalúrgico, textil, carne, alimentación, Luz y Fuerza, petroleros del Estado, portuarios, choferes de ómnibus y tranvías, telefónicos y telegrafistas, Ibid., 108

${ }^{13}$ Ibid., 108; Programa de la Falda, 1957, disponible en http://www.cgtargentinos.org/documentos.htm\#lafalda

${ }^{14}$ En 1958 el desarrollista Arturo Frondizi (Unión Cívica Radical Intransigente) asumió el gobierno. A pesar de que en las elecciones se sostuvo la proscripción al peronismo, el triunfo debió mucho al acuerdo realizado con Perón. Gobernó hasta marzo de 1962, cuando fue derrocado.
} 
funcionamiento institucional sino que lo haría con arreglo al código peronista reconociendo un solo sindicato por industria, lo cual se efectivizó en 1958. Se acordó también el levantamiento de las inhabilitaciones gremiales y la normalización de sindicatos y de la CGT.

Más allá de las diferencias que atravesaron al peronismo en función de las directivas de votar a favor de Frondizi o las campañas por el voto en blanco, un núcleo importante de dirigentes peronistas optó por una posición ortodoxa en apoyo a la institucionalización de las organizaciones gremiales. ${ }^{15}$ Fue precisamente este proceso el que erosionó la articulación que, en la acción, venían llevando adelante comunistas y peronistas, ya que los primeros se opusieron al intervencionismo del Estado y pregonaron la reanudación del Congreso Normalizador de la CGT. De manera que los gremios orientados por el Partido Comunista (PC) crearon 'el grupo de los 19', llamado luego Movimiento de Unidad y Coordinación Sindical - MUCS-. Por su parte, las 62 Organizaciones se erigieron como expresión de la posición dominante del peronismo al interior de los gremios.

El triunfo de Arturo Frondizi representó en términos económicos la profundización de una industrialización orientada al otorgamiento de generosas concesiones al capital extranjero para invertir en áreas estratégicas del desarrollo industrial. Durante estos años se redoblaron los esfuerzos por incrementar la productividad del trabajo. La reducción del empleo estatal, el congelamiento de salarios y las subas de tarifas e impuestos de 1959, incrementaron la lucha y la resistencia. A medida que la racionalización del sector público avanzaba, las contiendas obreras se endurecieron, aunque la represión hizo retroceder cuantitativamente la cantidad de huelgas. A nivel nacional, durante 1959 la cantidad de horas perdidas fue record. La tasa de ausencias en la industria por huelgas había trepado de 1.2 en 1958 a 5.7 en 1959 para bajar a 2.1 en 1960 y 0.41 en $1961 .^{16}$

La falta de cumplimiento de las promesas pactadas y la dinámica de la conflictividad con sus respuestas represivas, desvanecieron el optimismo inicial de la dirigencia sindical. ${ }^{17}$ La toma del Frigorífico Lisandro de la Torre en enero de 1959, el establecimiento del estado de sitio, la intervención de algunos sindicatos, la postergación de procesos eleccionarios en otros y la detención de referentes gremiales fueron elementos destacados que se profundizaron con la puesta en vigencia del Plan de Conmoción Interna del Estado - CONINTES-. ${ }^{18}$

\footnotetext{
${ }^{15}$ Daniel Parcero, Historia de ATE. Estatales en la inestabilidad. De los 'libertadores' a la dictadura de los monopolios, 4, Buenos Aires, CTA Ediciones, 2015, 81.

${ }^{16}$ Pablo Gerchunoff y Lucas Llach, El ciclo de la ilusión y el desencanto. Un siglo de políticas económicas argentinas, Buenos Aires, Emecé, 2007, 262.

${ }^{17}$ Mónica Gordillo, Córdoba en los '60. La experiencia del sindicalismo combativo, Córdoba, Taller General de Imprenta de la Secretaría de Extensión Universitaria de la Universidad Nacional de Córdoba, $1999,81$.

${ }^{18}$ Daniel James ha interpretado la etapa abierta en 1959 como de desmovilización y desmoralización de la clase obrera, lo cual explica la integración del aparato sindical al sistema político e institucional así como la burocratización en los sindicatos (James, 1991, 158-184). Las investigaciones de Alejandro Schneider han
} 
En agosto de 1959 había tenido lugar otro intento de dirección gremial conjunta: el Movimiento Obrero Unificado -MOU-, de corta existencia, desde donde se elaboró un programa de trece puntos firmado por las 62 Organizaciones, el MUCS y algunos gremios independientes. El programa contemplaba el cumplimiento de la Ley de Convenciones Colectivas de Trabajo, la normalización de la CGT, medidas contra la carestía de la vida y entrega de tierras para los trabajadores rurales. ${ }^{19}$

En octubre de 1960 se conformó la Comisión de los 20, integrada por las 62 Organizaciones y los 32 Gremios Democráticos, donde se excluyó la participación comunista. ${ }^{20}$ Los esfuerzos de la Comisión se concentraron en obtener la devolución de la CGT, la cual se concretó en marzo de 1961, al constituirse una Comisión Provisoria integrada por los sectores gremiales peronistas e independientes. Por las 62 Organizaciones, se destacaba la presencia de las figuras del sindicalismo peronista, como Andrés Framini y el metalúrgico Augusto Vandor que, con el correr de los años, se erigirían como expresiones de las corrientes internas que convivieron de manera tensional al interior del peronismo sindical. En efecto, aunque la vía dialoguista y pragmática fue la dominante en el gremialismo peronista, al calor de la conflictividad se fueron delineando dos grupos, los llamados intransigentes - también denominados "duros"-, vinculados con camadas de viejos dirigentes que en términos políticos perseguía como objetivo la vuelta de Perón; y otros ligados a Vandor, que procuraron integrar el aparato sindical al sistema político institucional de turno mediante la táctica de "golpear para negociar", propiciando la autonomía con respecto a Perón.

Durante el año 1961 la CGT llamó a tres huelgas generales, una de ellas de 72 horas, para frenar la caída del nivel de vida de los sectores populares y la proliferación de despidos y cesantías. Numerosos conflictos se desataron en empresas y ramas particulares contra el trabajo incentivado y el aumento de los ritmos productivos $\mathrm{y}$, en menor medida, por el atraso en el pago de sueldos y bonificaciones. Sobresalen aquí las luchas emprendidas por los trabajadores del riel contra el 'Plan Larkin', de resistencia al proceso de racionalización que se intentó imponer a través de la eliminación de redes ferroviarias, la privatización de servicios auxiliares, la modificación del régimen laboral y el despido de decenas de miles de trabajadores en todo el país. ${ }^{21}$

cuestionado la idea de derrota, subrayando la capacidad de movilización del movimiento obrero durante estos años adversos y su capacidad para protagonizar los procesos de tomas de fábricas de 1962/64 (Schneider, 2005, 133-137).

19 "Declaración de propósitos, 1959”, en: Santiago Senén González, El sindicalismo después de Perón, Buenos Aires, Galerna, 1971, 28-30; MUCS, "Declaración del MUCS sobre la unidad y la dirección única del movimiento obrero", Buenos Aires, $1^{\circ}$ de junio de 1960; MUCS, "Plenario Nacional del MUCS, Informe Central Resoluciones y Organizaciones Representadas”, Buenos Aires, 24-25 de junio de 1960; MUCS, "CGT. Un Congreso de unidad reclama la clase obrera. Posición del MUCS ante el próximo Congreso de la CGT", Buenos Aires, enero de 1963, 9-10.

20 "La dirección de la CGT", Nuestra Palabra, 27 de febrero de 1962, 8.

${ }^{21}$ Schneider, op. cit., 165-182. 
Durante los años siguientes, en 1962 y 1963, la economía argentina atravesó un proceso recesivo, con una importante caída de la producción industrial, restricción del crédito, caída de los salarios reales, crecimiento del desempleo, pagos a los empleados públicos en bonos que se llegaron a cotizar un $40 \%$ menos de su valor nominal y aumento de impuestos, todo lo cual impactó notablemente en los sectores populares. ${ }^{22}$ De modo que, tras la presidencia de Guido, la prioridad del gobierno del radical Arturo Illia $^{23}$ residió en lograr la revitalización de la economía a través de políticas expansivas monetarias, fiscales y salariales, lo cual se expresó en una recuperación durante 1964 y 1965 . No obstante esta relativa recuperación, la carestía de vida para los sectores obreros, los despidos y las dificultades para cerrar las negociaciones de convenios a los niveles esperados por los trabajadores, fueron recurrentemente denunciados como severos problemas por parte de las direcciones político sindicales del movimiento obrero.

En el contexto recesivo del año 1963 se registraron altos niveles de conflictividad labora y desde sectores combativos del peronismo se denunciaron elevadas cifras de desempleo. ${ }^{24}$ Fue durante el inicio de ese año cuando finalmente se normalizó la CGT, mediante un Congreso que eligió a José Alonso, del Sindicato del Vestido, como secretario general y que resultó de un acuerdo entre el sector vandorista y los independientes. Para entonces las 62 Organizaciones se constituyeron en la principal base de poder de Vandor, quien logró liderar el proceso de reconstitución de la CGT y conservar para los sectores peronistas los principales cargos directivos. ${ }^{25}$ La CGT lanzó así en el primer semestre de 1963 una campaña de reclamo por la situación económica, que se incrementó sobre finales de ese año y el año siguiente. En efecto, a comienzos de 1964 anunció la continuidad del Plan de Lucha, el cual contemplaba dos etapas, la más resonante de las cuales resultó del proceso de ocupación masiva y simultánea de todos los centros de producción y establecimientos industriales y de comercialización. Este proceso, acontecido en y desde las cúpulas sindicales, fue precedido y acompañado por una importante movilización de las bases. ${ }^{26}$ Tras el éxito del Plan de Lucha, las tensiones al interior del peronismo continuaron y, a nivel nacional, cristalizaron en la escisión que se estableció a fines del 1965 al constituirse por un lado, las 62 Organizaciones De pie junto a Perón, liderada por Alonso e integrada por los sectores 'duros', y, por el otro las 62 Organizaciones Leales a Perón, vandoristas.

\footnotetext{
${ }^{22}$ Gerchunoff y Llach, op. cit., 284-285 y 292-293.

${ }^{23}$ Tras el derrocamiento de Frondizi José María Guido, Presidente Provisional del Senado, gobernó el país hasta octubre de 1963. Arturo Illia, de la Unión Cívica Radical del Pueblo, asumió la Presidencia en esa fecha, hasta que fue derrocado por el Golpe de Estado del Gral. Onganía, en junio de 1966.

24 "Desocupación y hambre", Compañero, 23, 28 de noviembre de 1963, 5 y "Carestía de la vida. Los precios por las nubes", Ibid., 8 .

${ }^{25}$ James, op. cit., 221.

${ }^{26}$ Consultar al respecto: Alejandro Schneider, "Algunas consideraciones sobre las ocupaciones fabriles en la década de 1960", en Trabajadores, Buenos Aires, Herramienta, 2009, 91-127; Silvia Simonassi, "La conflictividad obrera en el Gran Rosario...”, op. cit.; Silvia Simonassi y Verónica Vogelmann, op. cit.
} 
En síntesis, en los primeros años que siguieron al Golpe, se desarrollaron a nivel organizativo, intentos unitarios que contenían a peronistas, comunistas e independientes, no obstante lo cual ya a comienzos de la década del sesenta fue visible en la escena nacional la notable preeminencia de los sectores peronistas, la consolidación del vandorismo, la relativa pérdida de relevancia de los sectores independientes y un notable desplazamiento de la presencia comunista en los espacios gremiales institucionales. De este modo, la dinámica de los procesos nacionales aportan claves para explicar los desarrollos locales/regionales, no obstante lo cual estudiar tradiciones gremiales específicas supone abordar las formas particulares - históricas-, en que estos legados, sentidos y valoraciones dominantes se configuran, con sus variaciones, en los procesos desarrollados a escala regional.

\section{Tradiciones obreras y sindicales rosarinas en vísperas de las elecciones de la CGT Regional Rosario de agosto de 1963}

Luego del Golpe de Estado de 1955 el panorama obrero y sindical rosarino fue adquiriendo ribetes cada vez más conflictivos. La ciudad de Rosario se convirtió en uno de los epicentros más dinámicos de la "Resistencia". En los primeros dos meses que siguieron al Golpe, el carácter convulsionado de la región se construía al compás de un abanico de protestas que implicaron huelgas, tomas de establecimientos industriales y de espacios barriales, marchas, manifestaciones y enfrentamientos con las fuerzas policiales. En ese año distintos nucleamientos gremiales fueron adquiriendo una notable presencia en el medio local, como el Comité de Recuperación Sindical, que contenía a sectores sindicales antiperonistas, principalmente socialistas, radicales y demócratas progresistas. ${ }^{27}$ Hacia fines del año 1955 dicho Comité denunciaba la presencia en Rosario de "elementos comunistas, que estaría operando en los gremios metalúrgicos, tabacaleros, tranviarios y frigoríficos, 'estamos -agregan- frente a una maquiavélica combinación peronista-comunista"”. 28

En efecto, la articulación en tensión de fuerzas peronistas y comunistas configuró una de las características destacadas de las tradiciones gremiales que, a escala regional se desarrollaron con notable fuerza y continuidad. Esto fue expresión de una construcción política ideológica tendiente a la unidad del movimiento obrero que lograría condensar en acciones y agrupamientos concretos, muchos de los cuales fueron resultado de la confluencia en los lugares de trabajo de obreros y activistas adscriptos o simpatizantes de distintos partidos y organizaciones.

\footnotetext{
${ }^{27}$ Marisa Armida y Beatriz Filiberti, “Entre la proscripción y el desarrollo (1955-1966)”, Alberto Pla (coord.), Rosario en la Historia (de 1930 a nuestros días) I, Rosario, UNR Editora, 2000, 289.

28 "El Ministro de Trabajo, esta mañana, habría explicado sobre la situación obrera. Del Comité de Recuperación Sindical”, La Tribuna, Rosario, 16 de noviembre de 1956.
} 
En relación a la presencia comunista en los procesos gremiales rosarinos durante estos años, esta situación ha sido reconocida por varios actores significativos. La versión del dirigente Héctor Quagliaro era que "el PC tenía gente en los sindicatos más que nada artesanales, los que alguna vez habían venido del anarco-sindicalismo, los mosaístas, los panaderos, los ladrilleros, los sindicatos de alrededores". ${ }^{29}$ Hugo Ortolani, por su parte, quien pasó por las filas del PC local para más tarde militar en el PRT, afirmaba: "En los primeros tiempos pos peronistas los PC lograron entrar a muchos gremios, sobre todo acá en Rosario. Me acuerdo que Osatinsky una vez (...) me dijo (él también había sido de la Juventud Comunista de Tucumán) 'Vos tuviste la suerte de militar en una de las juventudes comunistas más combativas y más proletarias de todo el país'. Y efectivamente acá el PC llegó a tener bastante: tenía la carne, tenía la construcción, tenía listas opositoras fuertes en muchos gremios; y por lo menos dos o tres gremios importantes ya te digo: carne y construcción seguro eran". 30

En efecto, los comunistas militaron activamente en los sindicatos locales y participaron sistemáticamente de los intentos de reconstitución de la CGT Regional Rosario. Lo cierto es que su presencia no era nueva en la ciudad, a varios de ellos la "Libertadora" los encontró fogueados en las luchas sindicales y políticas pues habían militado sindicalmente en gremios industriales durante el peronismo, se habían enfrentado a las direcciones peronistas de los sindicatos y a la represión estatal. Formaban parte de la ya citada "generación de los '40". 31

Hacia fines de los cincuenta y primeros años de la década siguiente, en algunos gremios dirigiendo, en otros integrando comisiones internas, en otros exhibiendo un importante activismo de base, la militancia comunista rosarina tenía presencia en metalúrgicos, La Fraternidad, ferroviarios, Luz y Fuerza, bancarios, construcción, vestido, papeleros, madereros, Mataderos, locutores, FASA, mecánicos, ceramistas, mosaístas, transporte, sanidad, químicos, carne, tabaco, textil y empleados de comercio, entre otros sindicatos. ${ }^{32}$

Su renovada presencia en la vida gremial rosarina se estructuró en distintos ámbitos de actuación, uno de ellos fue la Comisión Reorganizadora para la normalización de la CGT Regional Rosario, conformada tras la asunción de Frondizi. La Comisión fue impulsada por más de cuarenta gremios adheridos donde confluían sectores peronistas, comunistas e independientes. Tras sucesivas reuniones, el 14 de mayo de 1958, lograron que las autoridades hicieran entrega de los bienes físicos de la CGT Regional. Días después fuerzas

\footnotetext{
${ }^{29}$ Ojeda, op. cit., 69.

${ }^{30}$ Laura Pasquali, El PRT en Rosario. Entrevista con Luis Ortolani, Buenos Aires, Universidad de Buenos Aires, 2011, 26.

${ }^{31}$ González, "Biografía" op. cit.

32 MUCS, "Plenario Nacional del MUCS...", op.cit., 30; Partido Comunista, "El plan de lucha de la CGT. Debe triunfar por la acción unida de la clase obrera y el pueblo. Opinión de los dirigentes y militantes sindicales comunistas", volante, Rosario, 6 de abril de 1964 y Oscar González, S/ref. 4 folios.
} 
policiales clausuraron el local "por órdenes emanadas de la Subsecretaría de Trabajo y Previsión", 33 obturando el desarrollo del proceso de normalización en marcha.

Una de las expresiones más significativas del protagonismo de los activistas de esta corriente, fue el triunfo de una lista unitaria liderada por dirigentes comunistas en el Sindicato de la Carne de Rosario en 1961. ${ }^{34}$ Además de la presencia sindical, los comunistas tenían una fuerza muy importante en el movimiento vecinal de Rosario ${ }^{35}$ y habían conformado la Unión de Mujeres Argentinas - UMA-, desde donde realizaron frecuentes campañas contra la carestía de la vida. De modo que la presencia de un dinámico activismo comunista se articuló hacia fines de los cincuenta y primera mitad de los sesenta, con las diversas fracciones del peronismo sindical, tanto de viejo cuño como una nueva camada que, en correspondencia con lo acontecido en otras ciudades del país, se fogueaba en la nueva coyuntura.

En relación a los sectores del peronismo agrupados en las 62 Organizaciones, en 1958 se erigieron como defensores de la clausura de la CGT Regional Rosario al interior del movimiento obrero, haciendo públicos sus posicionamientos contrarios al proceso de normalización. Dirigentes destacados como José Pedernera, secretario general de Sanidad, e Ítalo Mingoni, de la Unión Tranviaria Automotor - UTA- declararon estar "en un todo de acuerdo" con la resolución de la Subsecretaría ya que la clausura se inscribía en la posición de "no innovar en la materia. Para ellos, la normalización se daría comenzando por la intervención de la CGT central y todas sus regionales y normalizando con elecciones libres a un breve plazo todos los gremios del país". 36

Estas controversias se inscribieron en disputas y rupturas más amplias que, como dimos cuenta, atravesaron a los sectores sindicales peronistas y comunistas en el marco del pacto electoral Perón-Frondizi. El comunismo cuestionaba el intervencionismo del Estado en las organizaciones gremiales y, en el marco de la Comisión Reorganizadora de la CGT Regional Rosario, llamaba a desconocer y rechazar toda intervención del Poder Ejecutivo. ${ }^{37}$ Asimismo, interesa subrayar la presencia de este sector del peronismo gremial caracterizado por sostener una manifiesta retórica anticomunista, expresada en acciones

33 "Representación gremial hácense cargo de la C.G.T. Comunicado de la subcomisión de prensa", La Capital, 14 de mayo de 1958 y "Motiva gestiones la situación vinculada a la regional de la C.G.T.", Ibid., 22 de mayo de 1958.

34 Véase Menotti, op. cit. y Vogelmann, “Conflictividad laboral en épocas de 'resistencia'...”, op. cit. Dominga Romero, Santiago Simón y Ramón Zarza eran militantes comunistas en el gremio de la carne: Partido Comunista, "El plan...", op. cit.

${ }^{35}$ Entrevista a Enrique Gigena, realizada por Verónica Vogelmann, Rosario, mayo 2016. Enrique Gigena es un reconocido dirigente comunista local perteneciente al gremio ferroviario, con una larga trayectoria de militancia política y sindical.

36 "Por la clausura de su local no se efectuó el plenario de la C.G.T.", La Capital, 21 de mayo de 1958 y Oscar González, "Biografía”, 10 de septiembre de 1978, Rosario, 13 folios.

37 "Motiva gestiones la situación vinculada a la regional de la C.G.T.", La Capital, Rosario, 22 de mayo de 1958. 
tendientes a obliterar el desarrollo de actividades y organizaciones unitarias que contuvieran a sectores gremiales adheridos a esta corriente. Este sector aparecerá posteriormente enrolado en la 62 Organizaciones de calle Balcarce.

Más allá de la temprana hegemonía que sectores de la derecha peronista tuvieron en las 62 Organizaciones rosarinas, no es tarea fácil reconstruir las características que la misma fue asumiendo ya que, tal como sucedió a nivel nacional, en su seno se expresaron las distintas corrientes internas del peronismo gremial. La heterogeneidad fue señalada por el referente de ATE Rosario Alberto Belloni: "En Rosario, las 62 Organizaciones necesitaron celebrar diez sesiones antes de avenirse a respaldar" la orden dictada por Perón de volcar los votos peronistas a favor del candidato de la Unión Cívica Radical Intransigente. ${ }^{38}$ En las calles también quedó expresada la confluencia de distintos sectores peronistas. Es el caso de un acto multitudinario de las 62 Organizaciones que reunió a dirigentes peronistas de distintos gremios expresando adhesiones a Perón y Evita y fijando posiciones críticas sobre el gobierno de Frondizi. Los oradores del acto sostuvieron prácticas y concepciones divergentes en relación con sus políticas de alianza con otras fuerzas, especialmente con el Partido Comunista. ${ }^{39}$

Los esfuerzos de reorganización de la CGT Regional Rosario continuaron, tanto en manos de sectores del peronismo que se negaban a quedar afuera, como de activistas sindicales comunistas e independientes. Esos esfuerzos se concretaron en la realización de plenarios con nutrida asistencia para elegir su secretariado, donde los metalúrgicos y textiles eran hegemónicos. Así aconteció cuando fueron seleccionados el metalúrgico Américo Pedernera, junto con otros dirigentes peronistas como Bustos de Textiles y José Freyre del Vidrio. ${ }^{40}$ Según Francisco Guarnieri "esa CGT continuó su labor unitaria dando solidaridad ante la lucha de distintos gremios". 41

De modo que a nivel local, durante todo el período resultaron frecuentes las acciones unitarias de sectores del peronismo local, independientes y comunistas (con la exclusión de los peronistas abiertamente anticomunistas). Estas convocatorias quedaron expresadas por ejemplo, en el paro general decretado por la CGT nacional para los días 1 y 2 de agosto de 1962, el cual fue precedido por diversas acciones, como contactos, reuniones y plenarios

\footnotetext{
${ }^{38}$ James, op. cit., 125.

39 "La ciudad estuvo anoche a merced de manifestantes que hicieron desmanes", La Tribuna, Rosario, 27 de septiembre de 1958, 3 y "Hubo desmanes al finalizar un acto en Rosario", El Litoral, Santa Fe, 27 de septiembre de 1958, 2.

${ }^{40}$ Ojeda, op. cit., 68.

41 "Francisco Guarnieri. Dirigente sindical de la construcción. Autobiografía", en Hernández, op. cit., 168. Francisco Guarnieri fue un referente de la "generación de los "40" del PC y del MUCS, del gremio de la construcción, formando parte de su Comisión Directiva sobre fines de la década de 1950 y principios de la siguiente: Oscar González, "Vida política de Francisco Guarnieri”, 22 de agosto de 1989. Oscar González integró también ese grupo, militó en el PC y MUCS y fue dirigente y activista en el gremio de Mataderos desde mediados de los cuarenta.
} 
que involucraron a las regionales del interior. En Rosario, una reunión de delegados, integrantes de comisiones internas y activistas, comandada por el secretariado de la CGT Regional, definió buscar "la mayor cohesión posible" para impulsar y garantizar el paro, llamando a los trabajadores a la unidad y a los rosarinos a no concurrir a cines o bares y no usar medios de transporte. Finalmente, numerosos gremios, en especial del sector industrial, adhirieron. Los del sector servicios lo hicieron en menor medida, aunque decidieron parar sindicatos claves como Ferroviarios y UTA. ${ }^{42}$

Debido al crecimiento de la conflictividad manifestado en la ciudad, la CGT Regional llamó, en el marco del plan de lucha nacional, a un acto público en el local de la Unión Ferroviaria. Entre los oradores, además de Américo Pedernera, hablaron dirigentes de Correos, Textiles, Telegrafistas y el dirigente comunista Ramón Zarza del Sindicato de la Carne. Por su parte, José Freyre, fue el encargado de leer el comunicado que convocaba a la movilización de todos los trabajadores, tras el reclamo de pago de sueldos en Correos, la restitución de la personería gremial a la Asociación Obrera Textil y el lockout declarado por el frigorífico Swift, entre otras demandas. ${ }^{43}$

Tanto la prensa local como las memorias (escritas y orales) relevan una importante actividad sindical unitaria. Fue también el caso de los actos convocados por la CGT Regional para los $1^{\circ}$ de Mayo, en los cuales era frecuente la presencia, como oradores, de referentes comunistas junto a dirigentes de gremios conducidos por independientes y peronistas. No obstante, y dando cuenta de la incómoda convivencia entre distintos sectores, en estos actos unitarios también fueron frecuentes los enfrentamientos entre los manifestantes peronistas y comunistas. ${ }^{44}$

Por cierto, dar cuenta de estas acciones unitarias no desplaza otra expresión de la política local: la persecución y la represión que se desató sobre el activismo sindical, teñidas de un marcado anticomunismo. La reunión preparatoria del paro de agosto de 1962 fue calificada por la policía como un acto "[que] no ha sido netamente gremial sino conducido y apoyado por elementos comunistas que no han hecho otra cosa que incitar a la violencia". Procurando intimidar a los trabajadores para los días de paro, la policía advirtió que "se

\footnotetext{
42 "La C.G.T. ha reafirmado los paros del $1^{\circ}$ y 2 de agosto", La Capital, Rosario, 13 de julio de 1962; "Comienza a la cero hora de mañana el paro de la C.G.T.", Ibid., 31 de julio de 1962 y "Dirigentes obreros se reunieron ayer en el C.G.T. regional”; Ibid., 28 de julio de 1962.

43 "Llevó a efecto la C.G.T. local un acto público la víspera", Ibid., 1 de septiembre de 1962. Ramón Zarza era un dirigente comunista, representante de la lista Marrón del Sindicato de la Carne por el frigorífico Swift, que había ganado las elecciones en febrero de 1961, permaneciendo al frente del mismo hasta octubre de 1962.

44 "Con diversos actos conmemorose el $1^{\circ}$ de Mayo", La Capital, 2 de mayo de 1959; "Con diversos actos celebrose el día del trabajador", Ibid., 2 de mayo de 1960; "En el Día de los Trabajadores se llevaron a cabo distintos actos. Hubo incidentes y golpes en la reunión pública patrocinada por la C.G.T.", Ibid. 2 de mayo de 1961.
} 
reprimirá todo intento de violencia y que los infractores serán puestos de inmediato a disposición de la justicia competente". 45

Como mencionamos, a partir de enero de 1959 el anticomunismo se agudizó, en particular debido al temor despertado en las clases dominantes por las consecuencias latinoamericanas de la Revolución Cubana, lo cual se expresó localmente en la represión a las luchas obreras tras la toma del Frigorífico Lisandro de la Torre y en la aplicación del Plan CONINTES. No obstante, y a pesar del anticomunismo reinante en el interior mismo del movimiento sindical, aún a comienzos de 1964 peronistas y comunistas convivían como aliados incómodos. De modo que la continuidad de las relaciones marca un rasgo distintivo de las tradiciones gremiales articuladas a sentidos y valores dominantes que postulaban la importancia de la unidad del movimiento obrero. Estos sentidos orientaron las prácticas sindicales en la escena rosarina de fines de los cincuenta y principios de los sesenta.

\section{De rupturas y continuidades. Emergencia y consolidación de una nueva camada de dirigentes obreros}

Como en otras ciudades de Argentina, en Rosario la "Resistencia" permitió la emergencia de una nueva camada de dirigentes obreros. Una de las expresiones más sobresalientes de este proceso tuvo lugar en el gremio de los trabajadores estatales, ATE Seccional Rosario y en particular entre los trabajadores pertenecientes a la División Paraná Inferior del Ministerio de Obras y Servicios Públicos de la Nación - MOP - o "el astillero". Allí en agosto del año 1958 y en cumplimiento de una resolución de asamblea sindical, se inició un paro de actividades, incluyendo a los empleados de la rama administrativa. ${ }^{46}$

Según Mario Aguirre, el blanco del descontento era el Director de la dependencia, "un ingeniero gorila [que] trataba a los compañeros de forma despectiva y otro tanto pretendió hacer con nuestra Junta Interna". La versión de Héctor Quagliaro resulta coincidente, el paro había sido declarado contra el Ingeniero Roca, un interventor radical, "un hombre mayor, un tipo represivo, durísimo con nosotros (...) cuando nos atendía a veces nos mostraba una pistola que tenía en su cajón, era de los comandos civiles". ${ }^{7}$

El paro fue acatado por dos mil quinientos trabajadores de ATE, pertenecientes a las ramas de marina, obreros y empleados de la División Paraná Inferior del MOP. Las proporciones que adoptó la medida de fuerza condujeron a los dirigentes del Sindicato a autorizar el

\footnotetext{
45 "Comienza a la cero hora de mañana el paro de la C.G.T. comunicado Policial", Ibid., 31 de julio de 1962.

46 "Pararon cuatro horas obreros del Estado y sigue la huelga municipal", La Tribuna, Rosario, 19 de agosto de 1958, 3.

${ }^{47}$ Aguirre, op. cit., 50 y Ojeda, op. cit., 45. Los comandos civiles aluden a los sectores antiperonistas que encararon acciones armadas contra el gobierno entre 1951 y 1955.
} 
mantenimiento de los servicios básicos para la descarga de las bodegas de los buques, a los fines de no entorpecer la reactivación del Puerto de Rosario. Con la modalidad de asistencia al lugar de trabajo y la realización de asambleas, los dirigentes informaban periódicamente sobre las gestiones realizadas y decidían acciones. Con el paso de los días y debido a la falta de respuestas, se paralizaron los servicios esenciales (grúa, remolcador, balizador y servicio de limpieza) y se resolvió enviar por segunda vez una delegación a Buenos Aires. ${ }^{48}$ Finalmente, tras anunciar que serían recibidos por el presidente Frondizi, la asamblea del MOP levantó el paro, al tiempo que se mantenían en estado de asamblea. En efecto, la prensa informó que dirigentes de ATE habían sido recibidos el día 9 de setiembre por el presidente. Poco antes de finalizar ese mes, pagaron los días de huelga al personal del MOP. Según la versión de Aguirre, el conflicto terminó "previa audiencia con el presidente Frondizi en casa de gobierno. Se retiró el jefe en cuestión y se abonaron los días de huelga". Quagliaro, por su parte, recordaba que "durante el paro las cosas no fueron fáciles, fueron bastante duras, tuvimos que negociar (...) yo propuse que a cambio del reconocimiento del conflicto, del pago de los días caídos y de la separación del ingeniero Roca, levantáramos el paro. La sugerencia fue aceptada y me nombraron integrante de la comisión negociadora". Las dificultades a las cuales hace alusión Quagliaro quedaron reflejadas por la prensa, que informó nuevos viajes de los dirigentes de ATE, tras el levantamiento del paro, para "seguir insistiendo con su reclamo" a los altos funcionarios.

Interesa subrayar que todas las fuentes resultan coincidentes en remarcar el estado asambleario que apuntaló el conflicto y que se convertiría en una práctica común en el gremio. Así lo recuerda Alberto Belloni, para quien en ATE “...ningún plenario tenía menos de 500 trabajadores, y hemos tenido asambleas de hasta mil y 1.200 en un gremio que tenía como afiliados 3.500 (...) Yo nunca permití que un dirigente del sindicato fuese el presidente de una asamblea. Las asambleas tenían que ser dirigidas por alguno que estaba elegido por las asambleas." 49 En este sentido, el conflicto analizado puede ser pensado como una coyuntura crítica que, al interior de un gremio particular, configuró un conjunto de prácticas que tendieron a reproducirse en legados.

Lo cierto es que este conflicto visibilizó, legitimó y otorgó reconocimiento a esa nueva camada de jóvenes ex alumnos de la Escuela de Aprendices del MOP, ahora trabajadores estatales. Para Aguirre, las bases del gremio asumieron el nacimiento de "los nuevos maradonas" frente a un gremio de "gestiones administrativas", mientras para Quagliaro esa lucha le "dio identidad gremial". Así, en enero de 1959, los líderes del conflicto llegaron a la conducción de ATE, mediante el triunfo de la lista Unidad y Acción. Héctor Quagliaro

\footnotetext{
48 "Responden al paro de la ATE 2500 trabajadores", La Tribuna, Rosario, 25 de agosto de 1958, 2 y "Paran servicios esenciales del MOP”, Ibid., 2 de septiembre de 1958, 3.

49 "Levantaron el paro en el M.O.P. Paraná Inferior", Ibid., 7 de septiembre de 1958, 4; "Audiencia con Frondizi”, Ibid., 9 de septiembre de 1958, 1; "Pagan los días de Huelga en el M.O.P.”, Ibid., 26 de septiembre de 1958, 1; Aguirre, op. cit., 50; Ojeda, op. cit, 47; "Dirigentes de ATE", La Tribuna, 25 de septiembre de 1958, 1. Entrevista con Alberto Belloni, en: James, op. Cit., 177.
} 
fue elegido Secretario General y Mario Aguirre Secretario Adjunto, lo cual representó el salto más allá de los confines del MOP, hacia el conjunto de los establecimientos que controlaba la Seccional Rosario de ATE, en esa ciudad y localidades vecinas.

A partir de ese momento, este grupo de dirigentes tuvo una sobresaliente gravitación en la escena gremial rosarina y en menor medida nacional. El alumbramiento de esta nueva dirigencia obrera y sindical fue liderado por Alberto Belloni, un "obrero ilustrado", apenas dos años mayor que Quagliaro y tres menor que Aguirre, pero reconocido por ambos como su "maestro". Formado en el marxismo, él mismo formador político y sindical, se fue acercando al nacionalismo de izquierda. Según la versión de Aguirre, el rol de formador no se limitó a lo estrictamente sindical, sino que incluyó el debate político sobre la actualidad argentina pos 1955 y el acercamiento a lecturas del marxismo clásico, de los principales referentes de la Revolución Rusa así como acerca de las luchas emancipadoras de América Latina. ${ }^{50}$ También Leticia Quagliaro confirmaba ese sesgo, el cual se expresaba en la organización de seminarios - pequeñas reuniones- de formación y de relevamiento de la prensa periódica. ${ }^{51}$ El propio Quagliaro afirmaba: "Alberto Belloni nos enseñó a leer a muchos de nosotros, a entender la política, a discutir... Nosotros casi ni habíamos leído". Lo definía como un ideólogo, un intelectual de izquierda que realizó su carrera políticosindical fuera del peronismo "pero no hacía antiperonismo". Quagliaro veía en Belloni una "fuerte tendencia trotskista", posiblemente pensando en esa formación teórico política y en su acercamiento a ciertos referentes de la "izquierda nacional" como Jorge Abelardo Ramos. $^{52}$

Lo cierto es que Belloni fue un activista sindical de proyección tanto local (en ATE y las 62 Organizaciones) como nacional (en ATE y participando en calidad de delegado en asambleas y congresos de las 62 Organizaciones y la CGT) ${ }^{53}$, al tiempo que organizó grupos de formación entre los jóvenes egresados de la Escuela de Aprendices del MOP, retomando tradiciones preperonistas del movimiento obrero. ${ }^{54}$ Héctor Quagliaro y Mario Aguirre, por su parte, se identificaron con el peronismo, al punto de recibir en Rosario y acompañar en su gira por el país a Isabel Perón en el año 1965. En tal sentido, su accionar sindical se fue definiendo contra el vandorismo y en la lealtad a Perón. Posteriormente, Aguirre se fue acercando a los sectores más radicalizados de la izquierda peronista.

\footnotetext{
${ }^{50}$ Ojeda, op. cit., 36-37 y 42-43; Aguirre, op. cit., 46.

51 Entrevista a Leticia Quagliaro, realizada por Silvia Simonassi, Rosario, enero de 2016. El fondo documental "Alberto Belloni” disponible en el Archivo Cedinci evidencia la importancia otorgada a los cursos de formación teórica y política, así como la práctica de relevamiento de fuentes periodísticas.

${ }^{52}$ Ojeda, op. cit., 36-37.

${ }^{53}$ Horacio Tarcus (dir.), Diccionario biográfico de la izquierda argentina, Buenos Aires, Emecé, 2007, 5758.

${ }^{54}$ Esto se manifiesta en su libro de 1959 Del anarquismo al peronismo, el cual se constituyó en herramienta de formación de cuadros obreros: Alberto Belloni, Del anarquismo al peronismo. Historia del movimiento obrero argentino, Buenos Aires, Editorial Punto de Encuentro, 2011.
} 
Son tres los factores que ayudan a comprender la inicial cohesión de este grupo de militantes. La Escuela de Aprendices del MOP representó un primer núcleo de socialización en oficios específicos orientados hacia el trabajo industrial. Una segunda instancia fue la experiencia de trabajo en la industria, pues en el MOP convivían "maquinistas, motoristas diesel, motoristas mecánicos, torneros, fresadores, carpinteros, carpinteros de barcos. Se construían canoas, lanchas. El sector donde estaba la herrería, la calderería, la soldadura, era el sector más grande (...) también producíamos oxígeno" ${ }^{55} \mathrm{Y}$ la tercera, la experiencia sindical en ATE. Esa experiencia resultaba más amplia, incorporaba activistas de diferentes centros de trabajo, algunos de configuración industrial, como las fábricas militares de Puerto Borghi - una localidad industrial ubicada al norte de Rosario, actualmente llamada Fray Luis Beltrán - y de Armas Portátiles Domingo Matheu, así como diferentes y múltiples dependencias y agencias del Estado donde primaba el tipo de trabajo administrativo, de recepción y de oficina.

El proceso de encumbramiento de esta nueva camada de jóvenes dirigentes sindicales, estuvo enmarcada en la conflictividad que recorrió al sector estatal en su conjunto, como resultado de los embates racionalizadores de las gestiones desarrollistas nacional, provincial y municipal. En efecto, municipales, trabajadores de Gas del Estado y del Matadero Municipal, se rebelaron en Rosario durante la segunda mitad de 1958. De hecho, una de las primeras acciones de la flamante directiva de ATE Rosario fue la adhesión al paro nacional dispuesto tras la toma del frigorífico Lisandro de la Torre, que tuvo un alto grado de acatamiento en la ciudad. Con la adhesión de la UOM, Sindicato de la Carne, ATSA, UPCN, ATE, UOCRA, Unión Obrera Maderera, la ciudad estuvo "virtualmente paralizada" y los militares debieron garantizar la prestación del servicio de pasajeros de la ciudad. $^{56}$

La proyección sindical de este grupo se amplió en el orden local cuando Mario Aguirre fue designado en el primer semestre de 1960 en la CGT Regional Rosario en reemplazo de Damián Martínez, del SOEVA. ${ }^{57}$ En el orden nacional, se efectivizó a través de la breve participación de Quagliaro como Secretario General en el Consejo Directivo provisional de la ATE Nacional en 1959 y tal como señalamos anteriormente, del propio Belloni.

En síntesis, esta nueva camada se configuró como parte de la conflictividad de fines de la década del cincuenta y a través de prácticas de consulta y participación de los trabajadores en las instancias resolutivas. En ese marco, el conflicto desatado en el Ministerio de Obras Públicas en 1958 puede ser pensado como una coyuntura crítica, en tanto momento clave a través del cual se establecieron formas organizativas que se transformaron en legados y confluyeron en la construcción de esta nueva tradición gremial. Hacia adentro, un rasgo distintivo de esta camada fue la amplia formación política y sindical de los dirigentes,

\footnotetext{
${ }^{55}$ Ojeda, op. cit., 35.

${ }_{57}^{5}$ Armida y Filiberti, op. cit, 297.

57 Aguirre, op. cit. 49 y 59. 
compuesta por un amplio repertorio de lecturas y debates clásicos del marxismo y de la más nueva "izquierda nacional”, con sus ingredientes nacionalistas y latinoamericanistas.

\section{De la conquista de la CGT Regional Rosario al episodio de Cerveceros}

El triunfo de la lista encabezada por Héctor Quagliaro en las elecciones de la CGT Regional Rosario de agosto de 1963 constituyó el más sobresaliente capítulo de la proyección sindical a escala local/regional del grupo de ATE Rosario. Secundaron a Quagliaro dirigentes de La Fraternidad, Textiles, Calzado, Aguas Gaseosas y Unión Ferroviaria, además del Secretario General del Sindicato de Locutores, perteneciente al MUCS y al PC. ${ }^{58}$

La lista Blanca resultó así, de acuerdo a sus propios arquitectos, por un lado, de las negociaciones con sectores de la vieja dirigencia sindical peronista que expresaban posiciones unitarias y por otro, de la estratégica alianza con los sectores gremiales del comunismo local. Así lo reconocía el propio Quagliaro, para quien los que sustentaron posiciones unitarias fueron los dirigentes de la gestión saliente de la CGT, el metalúrgico Pedernera y el textil Bustos. ${ }^{59}$ También los aliados del PC reconocían que la unidad devino de una "ronda de consulta y cambio de opiniones" entre las 62 Organizaciones, algunos independientes y el MUCS. Para Guarnieri este resultado mostró el triunfo de un "principio unitario". 60

La participación de los comunistas resultó imprescindible para el triunfo de la Lista Blanca, debido al ya analizado papel desempeñado en el panorama sindical local. No obstante, esta fue una de las razones de la oposición de los independientes y de la derecha peronista. Es más, en el contexto de las negociaciones y alianzas para las elecciones, y durante los meses posteriores, en Rosario éstos últimos se mantuvieron agrupados y escindidos del resto, conformando las 62 Organizaciones de calle Balcarce. La incorporación de César Granollers, del Sindicato de Locutores, a la CGT Regional Rosario, provocó la ruptura de los sectores independientes y peronistas anticomunistas y el desconocimiento del plenario. Finalmente, el dirigente del MUCS asumió como Secretario de Organización, los sectores descontentos se retiraron y solicitaron públicamente la intervención de la CGT nacional para evitar una "profunda división en el movimiento obrero rosarino". 61

Promediando el año 1963 existían, en el escenario rosarino, las 62 Organizaciones Leales de calle Balcarce en abierta hostilidad con la dirección de la CGT Regional Rosario y, hacia

\footnotetext{
${ }^{58}$ Elecciones CGT Rosario, "Voto Lista Blanca", 1963, 1 folio.

${ }^{59}$ Ojeda, op. cit., 67.

${ }^{60}$ El testimonio de Guarnieri en Hernández, op. cit., 169.

61 "De nulo califica un sector laboral al reciente plenario", La Capital, Rosario, 30 de agosto de 1963; González, “Anécdotas”, op. cit., 1963.
} 
principios de 1964 las 62 Organizaciones calle Córdoba cuyo secretario general era Guillermo Garrigues. ${ }^{62}$ Como adelantamos, en estos alineamientos Quagliaro se fue posicionando como un hombre ligado al sector peronista de los "duros", vinculado con el liderazgo de Framini e integrante de las 62 De Pie junto a Perón. En sus propias palabras, "nosotros nos opusimos a esa maniobra del peronismo sin Perón”, “...nosotros no dejamos de creer que Perón iba a volver (...) para nosotros era una bandera (...) eso nos servía como imán que atraía y convocaba gente. Pero no participábamos de las decisiones políticopartidarias. La nuestra era más que nada, una adherencia afectiva". "Éramos la izquierda peronista". 63

Además de la cristalización de disputas al interior de las corrientes gremiales peronistas, la relación entre comunistas y peronistas se expresó en términos de una convivencia difícil en la cotidianeidad de la vida sindical local y en numerosas acciones anticomunistas, más frecuentes a partir de 1960. Una muestra elocuente de dicho accionar fue el allanamiento del Sindicato de Locutores, en setiembre de 1963, cuando la policía irrumpió en una reunión nacional de la UMA en el marco de un procedimiento relacionado con la represión de actividades comunistas. Durante el operativo detuvieron a cincuenta y seis mujeres y secuestraron materiales de propaganda. Luego de estos hechos, la filial rosarina del sindicato fue intervenida por la Junta Directiva Central con sede en Buenos Aires. El delegado interventor y presidente de dicha Junta defendía su actuación en términos de "reafirmar su tradicional actitud de condenación a todo extremismo, sea de izquierda o de derecha..." En este marco, se registraron también procedimientos anticomunistas en domicilios particulares, con secuestros de materiales y detenciones. ${ }^{64}$

Otro episodio relevante fue la desmedida represión desatada en enero de 1964 contra una movilización orientada a reclamar contra la carestía de vida, convocada por UMA y el Partido del Trabajo y Progreso. En las puertas del diario La Capital e inmediaciones los manifestantes fueron reprimidos con camiones hidrantes. Hubo intentos de armar barricadas, enfrentamientos "cuerpo a cuerpo", insultos y el saldo de varios heridos. ${ }^{65}$

Solo un mes después, la violencia llegó a un extremo mucho más grave, cuando un plenario ampliado de la CGT Regional Rosario realizado en el Sindicato de Cerveceros de la ciudad,

\footnotetext{
${ }^{62}$ Las 62 Organizaciones calle Balcarce estaban lideradas por José Pedernera (Sanidad), Italo Mingoni (UTA), Juan Gaetán (gastronómicos), Antonio Perollo (garaje), Oscar Militello (Madera). A principios de 1964 declaraban estar constituidos por 31 gremios y 9 agrupaciones: "Los sindicatos procesan los episodios. Comunicado de las 62 Organizaciones. Las "62" Leales", La Tribuna, Rosario, 26 de febrero de 1964.

${ }^{63}$ Ojeda, op. Cit. 76, 91, 83.

64 "Abogados defensores de unas detenidas dan un comunicado" y "La filial local de la S. A. de Locutores ha sido intervenida", La Capital, 12 de septiembre de 1963 y "Se secuestró de un domicilio diverso material comunista", Ibid., 29 de septiembre de 1963.

65 "Luego de un acto hubo varios incidentes", La Capital, 21 de enero de 1964 y "Derivaciones de los tumultos de ayer en la zona céntrica: ¿hay malestar en la policía?”, La Tribuna, 21 de enero de 1964; Oscar González, "Cerveceros (biografía)", 1964.
} 
donde se discutía el Plan de Lucha, fue interrumpido por un tiroteo que dejó tres muertos y varios heridos. ¿Qué pasó en Cerveceros? Según el relato de la prensa, tras la intervención de Quagliaro los ánimos se fueron caldeando hasta que desde un sector se comenzó a corear "ni yanquis ni rojos", mientras tiraban volantes con las leyendas "Movimiento Nacional Tacuara" y "Por la Revolución Sindical Argentina". Inmediatamente comenzaron los disparos, trescientos o cuatrocientos según las fuentes. El Litoral afirmó que entre los aproximadamente doscientos asistentes predominaba la "extrema izquierda", aunque otras fuentes resaltaban el rasgo de heterogeneidad de los asistentes, incluidos militantes de organizaciones estudiantiles y vecinales, mujeres y niños y subían la cantidad de participantes a trescientos. ${ }^{66}$

Para la policía se había tratado de la "trágica rivalidad de ambos grupos", al igual que para parte de la prensa, el tiroteo había resultado del enfrentamiento entre nacionalistas y comunistas. Para otros, los balazos provinieron del exterior, ${ }^{67}$ mientras la publicación peronista Compañero lo caracterizó como un ataque a mansalva contra los asistentes al plenario, negando la versión de que se había tratado de un enfrentamiento sindical. Compañero acusó a los Comandos Civiles y a la connivencia con autoridades oficiales y policiales, que no habían actuado a pesar de haber asistido al plenario: el ataque según esta interpretación, había sido planificado y dirigido por la Secretaría de Inteligencia del Estado - SIDE-. Había sido responsabilidad de agentes provocadores infiltrados en organizaciones de derecha o izquierda, se trató "de un plan fríamente meditado y criminalmente llevado a la práctica por parte del mecanismo de acción psicológica y servicios de informaciones de las minorías fraudulentas encaramadas en el poder". ${ }^{6}$

Los muertos fueron todos militantes peronistas y del Movimiento Nacional Tacuara -MNT-, una organización visiblemente identificada con la derecha peronista: Víctor Militello, dirigente del Sindicato de la Madera y referente de las 62 Organizaciones de calle Balcarce, Antonio Giardina secretario de finanzas de la Juventud Peronista y Ángel Bertoglio perteneciente a Tacuara. Tenían entre 20 y 26 años. Entre los heridos, se encontraba Francisco Guarnieri, el ya citado dirigente comunista del gremio de la construcción, además de otros integrantes de Tacuara y un agente policial. ${ }^{69}$

El Movimiento Tacuara, también se pronunció. Desde la exaltación del nacionalismo, "por Dios y por la Patria" contra el liberalismo y el comunismo, contra "capitalistas, marxistas e

\footnotetext{
66 "Un acto organizado por la CGT en Rosario tuvo trágico desenlace", El Litoral, 25 de febrero de 1964, 2; "Anoche en la asamblea de la CGT Local: 300 disparos, 3 muertos y 5 heridos", La Tribuna, 25 de febrero de $1964,1$.

67 "Un acto organizado por la CGT...", op. cit.; "Detalles del trágico episodio ocurrido en el plenario obrero", La Capital, 26 de febrero de 1964; "Hay versiones sobre origen del tiroteo", La Tribuna, 25 de febrero de 1964, 1.

68 "Rosario. Siniestro plan oficial", Compañero, 36, 4 de marzo de 1964.

69 "Anoche en la Asamblea...", op. cit.; "Se halla confundida y estacionada la pesquisa del sangriento incidente registrado en el plenario gremial", Ibid., 26 de febrero de 1964, 2.
} 
izquierda nacional unidos contra el pueblo", denunciaron que "comunistas protegidos por la policía" habían sido responsables del asesinato de los militantes del MNT y de la Resistencia Peronista. ${ }^{70}$

La CGT Regional Rosario, por su parte, declaró un paro de 12 horas y convocó a asistir al entierro de "nuestros desaparecidos compañeros". Paralelamente repudiaron enérgicamente el atentado y exigieron pronta y amplia investigación. Las hostilidades que atravesaban al movimiento obrero se pusieron nuevamente de manifiesto con renovado vigor. Mientras que las 62 Organizaciones con sede en calle Córdoba explicitaba su condena y pedía efectiva investigación de los hechos, las 62 Organizaciones leales de calle Balcarce y gremios afines, denunciaban "la cobarde agresión comunista", a la vez que destacaba "la actitud suicida del secretariado regional Rosario que ha permitido aun dentro de su secretariado la infiltración comunista". ${ }^{71}$

¿Qué representó Cerveceros? ¿Cuál fue su relevancia para el tema que estamos analizando? Luego de estos episodios, la andanada anticomunista llegó al fin a la propia CGT Regional Rosario, pues a pocos meses de la asunción de la nueva directiva, fue desplazado el representante del MUCS. Según Quagliaro, tras Cerveceros, se rompió el acuerdo entre peronistas y comunistas que había permitido ganar la Regional: "Nadie sabía nada concreto y uno intentaba no acusar a uno ni a otro, para no involucrarse en una cosa que no había decidido, que no había discutido. Pero allí se terminó el acuerdo que teníamos con el MUCS, Granollers fue separado de la conducción de la CGT"; y agregaba que el "hecho ratificó que Rosario era un lugar de mucha confrontación política, muchas cosas se resolvían a los tiros...". 72 Para los comunistas los sucesos ocurridos en Cerveceros significaron un claro revés en el proceso de crecimiento en el ámbito sindical y en su política de unidad de acción. En palabras de un referente comunista del gremio ferroviario "a nosotros políticamente nos mató la criatura antes de nacer". ${ }^{73}$

Tres días después de Cerveceros, fueron baleados en el centro de la ciudad, a plena luz del día y ante numerosas personas, los abogados comunistas Guillermo Kehoe y Adolfo Trumper, tras lo cual fue apresado en las terrazas linderas al local de la CGT Telmo Galarza, un dirigente de su secretariado, suegro de uno de los muertos en Cerveceros, que luego se declaró culpable de este ataque. Iba tomando forma en el caso de Cerveceros la hipótesis del "comando" traído de afuera para garantizar la impunidad. Y en el caso del ataque a los abogados, la convicción de que respondía a una venganza por esos acontecimientos. Es de destacar el impacto que estos hechos tuvieron en la ciudad, donde la prensa le dedicaba sus portadas y extensas notas a las novedades al respecto, en tanto

\footnotetext{
${ }^{70}$ MNT Comando La Plata, volante s/f.

71 "Un acto organizado por la CGT...", El Litoral, op. cit. "Se tomó declaración a los heridos en Rosario", La Tribuna, 27 de febrero de 1964; "Los sindicatos procesan los episodios”, Ibid., 26 de febrero de 1964, 3.

${ }^{72}$ Ojeda, op. cit., 78-82.

${ }^{73}$ Entrevista a Enrique Gigena, op. cit.
} 
presagiaba una escalada de violencia, de venganzas y contra venganzas. No obstante, el segundo de los episodios mereció un más unánime repudio debido a que se trataba de profesionales, baleados en la calle y en el centro de la ciudad. ${ }^{74}$ Además, si el primer episodio se desarrolló en un local sindical, el tiroteo se realizó en las calles céntricas de la ciudad. En contraste con este tratamiento de la prensa local, las memorias escritas y orales retoman Cerveceros como el episodio que condensó las contradicciones, las tensiones y los conflictos que palpitaban en el escenario obrero y sindical local.

El atacante de los abogados era dirigente del Sindicato de la Construcción, que era para los comunistas "una cueva de gangsters y provocadores que roban sumas millonarias a los obreros", donde "se asientan y actúan sectores de la juventud peronista, en particular los Tacuara, y se planean ataques...”. De hecho, en línea con las denuncias realizadas por el PC, la prensa local relataba durante estos meses diversos hechos de violencia que tuvieron como protagonistas a sectores de la Unión Obrera de la Construcción. En particular el secuestro y desaparición del dirigente sindical Pedro Huergo, que tuvo en vilo a la prensa durante algunas semanas y que finalmente mereció serias denuncias que involucraban al dirigente nacional Rogelio Coria no sólo con turbias cuestiones gremiales, sino también con delitos comunes. $^{75}$

Tras el desplazamiento del MUCS de la conducción de la CGT Regional Rosario, los comunistas cuestionaron a dicha Central señalando que si bien había dado pasos hacia la unidad, se hallaba "trabada y retrocediendo" por la "permanencia en su seno de los elementos antiunitarios y propatronales, que a punta de metralletas siguen exigiendo acciones anticomunistas y apañan a los asesinos Tacuaras." Denunciaban además la actuación de "bandas asesinas" en las asambleas sindicales. ${ }^{76}$

Tras los atentados, "las fuerzas político y gremiales a las que pertenece Galarza", como el Comando Rosario de la Juventud Peronista, junto con figuras nacionales como Framini y Vandor, organizaron un acto en apoyo al detenido. En el contexto del Plan de Lucha de la CGT, el acto fue prohibido por las autoridades, sin embargo en la fecha convenida, Framini se hizo presente y se realizaron manifestaciones que tuvieron como eslogan la "libertad de Galarza". Las manifestaciones fueron reprimidas por la policía. En los comunicados de delegados e interventores del partido Justicialista se acusó al Gobernador de la Provincia de

\footnotetext{
74 "Balearon hoy a Keohe y Trumper", La Tribuna, 28 de febrero de 1964; "Desespera salvar al Dr. G. Kehoe", Ibid., 29 de febrero de 1964.

${ }^{75}$ Partido Comunista, "El plan...", op. cit.; "Buenos Aires: la policía cree que Huergo es un mistificador. Rosario: no encuentran juez", La Tribuna, 31 de enero de 1964 y "Una denuncia pone nuevamente sobre el tapete graves hechos en el gremio de la construcción", Ibid., 18 de febrero de 1964.

${ }^{76}$ Partido Comunista, "El plan...", op. cit. El MUCS denunciaba a nivel nacional a las 62 Organizaciones por copar la dirección de la CGT, exigía la realización de un Congreso Normalizador, ponía en duda su disposición para movilizar a las bases obreras, además de permitir la actuación de las bandas de derecha en su interior, en: MUCS, "Para el éxito del Plan de acción de la CGT, ¡luchemos por la unidad sin exclusiones en la central obrera!", volante, Buenos Aires, 5 de agosto de 1964.
} 
Santa Fe de "complacencia para ciertos extremismos". ${ }^{77}$ Es interesante destacar la presencia de Framini en estas movilizaciones en defensa del "Tío Galarza"78 ya que podría estar indicando cierto acercamiento y unidad de acción por parte de las distintas fracciones político-sindicales peronistas y el inmediato desplazamiento de los comunistas.

\section{Conclusiones}

En este trabajo hemos abordado algunas dimensiones constitutivas de las tradiciones obreras y sindicales rosarinas en los primeros años sesenta, focalizando la atención en el accionar de diferentes corrientes político- gremiales que disputaron en el interior del mundo sindical y deteniéndonos en el análisis de una nueva camada de activistas sindicales provenientes de ATE.

Partimos de reconocer la importancia de los procesos de lucha y organización desarrollados a escala nacional en la resistencia obrera al Golpe de Estado de 1955 y contra los ataques sistemáticos que sufrieron los trabajadores sobre sus derechos y conquistas históricas. En esos años, la conflictividad laboral se orientó a recobrar la plena institucionalidad de las organizaciones gremiales, a exigir aumentos salariales que paliaran la carestía de la vida y a resistir los incrementos de la productividad del trabajo y los despidos. Estos reclamos son los que motorizaron la protesta obrera también en el ámbito local, a los cuales se le sumaron conflictos obreros que ponían en cuestión las jefaturas al interior de los lugares de trabajo, como aconteció en 1958 en el Ministerio de Obras Públicas.

En los primeros años que siguieron al Golpe de Estado, a nivel nacional adquirió importancia la acción unitaria de trabajadores adscriptos a diversas corrientes políticogremiales, peronistas, comunistas e independientes; no obstante, a comienzos de la década del sesenta fue visible la notable preeminencia de los sectores peronistas en los espacios sindicales a nivel nacional. Rosario, aunque no se apartó de esta tendencia, sí se distinguió por la presencia de un dinámico activismo comunista, lo cual constituyó una de las características destacadas de los procesos gremiales en el orden local/regional durante todo el período analizado. Como hemos abordado, este activismo se articuló con fracciones del peronismo sindical que sostenían posiciones unitarias, tanto de viejo cuño como con una nueva camada que surgió en esta coyuntura, convirtiéndose en otro de los rasgos duraderos y característicos del escenario local. Las acciones unitarias se desplegaron en un contexto de persecución y represión generalizadas sobre el activismo sindical, teñidas de proscripciones al peronismo y de un marcado anticomunismo. En este contexto, sobresale

\footnotetext{
77 "El obrero Galarza pidió garantías y fue trasladado a la cárcel. Postergan un acto", La Tribuna, 6 de mayo de 1964 y "La prohibición del acto justicialista dio anoche lugar a la acción policial: petardos, corridas y chapuzones", Ibid., 19 de mayo de 1964.

${ }^{78}$ Así lo recuerda Quagliaro y agrega “...era también un hombre valiente, pero con ideas bastantes fascistoides. Él tenía mucho afecto por nosotros", en: Ojeda, op. cit., 80.
} 
también la presencia de ciertos sectores del peronismo que durante todo el período sostuvieron una clara retórica anticomunista.

De manera que, la pregunta acerca de las tradiciones gremiales, de los sentidos y valores dominantes que orientaron las prácticas sindicales supuso abordar la aparición y consolidación de la nueva camada de activistas de ATE, expresión de una nueva tradición gremial. Así, uno de los procesos destacados fue el surgimiento de este grupo de dirigentes jóvenes provenientes de la Escuela de Aprendices del Ministerio de Obras Públicas, activistas sobresalientes en uno de los tantos conflictos laborales que signaron la ciudad hacia fines de la década del cincuenta. La particular experiencia compartida en el lugar de trabajo explica la inicial cohesión de este grupo de militantes, la Escuela de Aprendices y el trabajo en el MOP representaron para los trabajadores del Estado núcleos de socialización en oficios específicos orientados hacia la labor industrial. Además, la conformación de esta nueva camada de dirigentes estuvo atravesada por un proceso de formación sindical y político conducido por el "obrero ilustrado" Alberto Belloni, quien ejerció durante parte del período un papel de liderazgo en la formación y organización sindical de este activismo, retomando tradiciones preperonistas del movimiento obrero, releyendo el peronismo y acudiendo al marxismo. Por último, hemos destacado la importancia del conflicto de 1958, que operó como una coyuntura crítica a través de la cual se establecieron rasgos particulares en las formas organizativas, tendientes a la participación de los trabajadores y al estado asambleario, que se transformaron en legados y confluyeron en la construcción de esta nueva tradición gremial.

El grupo de ATE Rosario llegó a ostentar una sobresaliente gravitación en la escena gremial rosarina, particularmente a partir del triunfo de la lista encabezada por Héctor Quagliaro en las elecciones de la CGT Regional Rosario en agosto de 1963. Hemos subrayado que ese encumbramiento fue posible gracias a la presencia comunista garantizada por la elección de un dirigente del MUCS como Secretario de Organización; y destacamos que esta alianza fue tejida por los dirigentes peronistas de la gestión saliente de la citada CGT que sustentaban posiciones unitarias, mostrando la complejidad del proceso.

En efecto, la apertura al diálogo y la unidad de acción entre sectores comunistas y peronistas que ostentaban posiciones unitarias es una de las características distintivas de las tradiciones gremiales del período y constituye uno de los legados más significativos a través del cual se configuró el accionar de la nueva camada de militantes proveniente de ATE. El accionar unitario devino también en disputas al interior de las corrientes gremiales peronistas, en una convivencia incómoda entre peronistas con políticas pro-unidad y comunistas en la cotidianeidad de la vida sindical local y en numerosas acciones anticomunistas, más frecuentes a partir de 1960. El tiroteo de Cerveceros, con el saldo de tres muertos y varios heridos, así como el posterior atentado contra dos abogados comunistas, además de diversos embates de menor repercusión, se inscriben claramente en ese escenario de luchas y fricciones. 
Todos esos episodios determinaron el desplazamiento de los comunistas de la CGT Regional Rosario y el consecuente rompimiento de los acuerdos. No obstante, la presencia de unos y otros en el mundo obrero y sindical local, en las bases y en posiciones de dirección, no desapareció, aunque la investigación sobre la composición de las comisiones internas y los cuerpos de delegados y su papel en el orden local/regional es una labor pendiente. Queda abierta también la pregunta acerca de la reconfiguración del panorama sindical local posterior a Cerveceros y las maneras en que dicho proceso incidió en la radicalización de las luchas obreras de fines de la década del sesenta. Por último, queda pendiente el análisis de otras corrientes sindicales que, como la izquierda trotskista, dinamizaron la actividad gremial rosarina.

\section{Bibliografía}

Águila, Gabriela y Viano, Cristina, “Trabajador@s y militantes: sobre algunas vertientes de la izquierda peronista del norte al sur del cordón industrial del Gran Rosario entre 1969 y 1976. Una aproximación desde la historia oral", Anuario de la Escuela de Historia, 19, 2002.

Armida, Marisa y Filiberto, Beatriz, Entre la proscripción y el desarrollo (1955-1966), Pla, Alberto (coord.), Rosario en la Historia (de 1930 a nuestros días), I, Rosario, UNR Editora, 2000.

Balvé, Beba y Balvé, Beatriz, El '69. Huelga politica de masas. Rosariazo, cordobazo, rosariazo, Buenos Aires, Editorial Contrapunto, 1989.

Cambiasso, Mariela y Longo, Julieta, "La noción de experiencia en E. P. Thompson: una propuesta para el análisis de los casos de alimentación y comercio en la posconvertibilidad", Revista Rey Desnudo, 3: II, 2013.

Carminati, Andrés, "Elementos extraños con brazaletes rojos". Radicalización obrera y lucha armada en una metalúrgica mediana de la ciudad de Rosario (1973-1976)" en Ciriza, Alejandra, Graselli, Fabiana y Rodríguez Agüero, Laura (comp.) La centralidad de la política en los 70. Lecturas sobre un tiempo disruptivo, Mendoza, EDIUNC (en prensa).

Cerio, Débora, "Revisando los relatos sobre una experiencia de organización obrera: el Sindicato de Obreros y Empleados Petroquímicos Unidos en los años '70", en Taller. Revista de Sociedad, Cultura y Política, 24, 2007.

Ceruti, Leónidas y Resels, Mariano, Democracia directa y gestión obrera. El SOEPU, la intersindical de San Lorenzo y la coordinadora de gremios. 1962-1976, Rosario, Ediciones del Castillo, 2006.

Gerchunoff, Pablo y Lucas Llach, El ciclo de la ilusión y el desencanto. Un siglo de políticas económicas argentinas, Buenos Aires, Emecé, 2007.

Gindin Julián, "La tradición sindical y la explicación de las prácticas sindicales. Conclusiones de una comparación internacional sobre los docentes del sector público", Revista Latinoamericana de Estudos do Trabalho, 16: 26, 2011.

Gordillo, Mónica, Córdoba en los '60. La experiencia del sindicalismo combativo, Córdoba, Universidad Nacional de Córdoba, 1999.

Hobsbawm, Eric, La invención de la tradición. Barcelona, Crítica, 2002. 
James, Daniel, Resistencia e integración. El peronismo y la clase trabajadora argentina, 19461976, Buenos Aires, Siglo XXI, 2005.

Menotti, Paulo, "Al sur, un faro de luces y sombras. Historias de militancia, trabajo y explotación en el Swift. La experiencia de los comunistas", tesis de licenciatura UNR, inédita, 2008.

Novelo, Victoria, "La cultura obrera, una contrapropuesta cultural", Nueva Antropología, 232: VI, México, marzo de 1984.

Parcero, Daniel, Historia de ATE. Estatales en la inestabilidad. De los 'libertadores' a la dictadura de los monopolios, 4, Buenos Aires, CTA Ediciones, 2015.

Pasquali, Laura, El PRT en Rosario. Entrevista con Luis Ortolani, Buenos Aires, Universidad de Buenos Aires, 2011.

José Pérez y Viano, Cristina, "El 69: del mayo rosarino al Rosariazo", en Patricia Berrotarán y Pablo Pozzi (comp.), Estudios inconformistas sobre la clase obrera argentina, 1955-1989, Buenos Aires, Letra Buena, 1994.

Ramalho José Ricardo y Marco Aurélio Santana, "Tradição sindical e as mudanças econômicas dos anos de 1990. O caso dos metalúrgicos do Rio de Janeiro", Rio de Janeiro, Trabalho e tradição sindical no Rio de Janeiro. A Trajetória dos metalúrgicos, DP\&A editora - FAPERJ, 2001.

Salas, Ernesto, La resistencia peronista. La toma del Frigorífico Lisando de la Torre, Buenos Aires, Retórica Ediciones, Altamira, 2006.

Schneider, Alejandro, Compañeros. Trabajadores, izquierda y peronismo en la Argentina, 19501973, Buenos Aires, Imago Mundi, 2005.

Schneider, Alejandro, "Algunas consideraciones sobre las ocupaciones fabriles en la década de 1960", en Trabajadores, Buenos Aires, Herramienta, 2009, 91-127.

Scoppetta, Laura y Torres, Pablo, "La apuesta armada. Notas sobre la política sindical del PRT-ERP en el Gran Rosario (1965-1976), seminario regional, inédito, 2014.

Senén González, Santiago, El sindicalismo después de Perón, Buenos Aires, Galerna, 1971.

Simonassi, Silvia, "Conflictividad laboral y políticas disciplinarias en la industria metalúrgica de la ciudad de Rosario 1973-1976”, Anuario IEHS 22, Tandil, 2007.

Simonassi, Silvia, "La conflictividad obrera en el Gran Rosario durante la década de 1960: rediscusión de las principales hipótesis y propuesta de investigación", ponencia XV Jornadas Interescuelas Departamentos de Historia, Comodoro Rivadavia, 2015.

Simonassi, Silvia y Vogelmann, Verónica, "Tradiciones gremiales, conflictividad y organización obrera en Rosario durante la década del sesenta”, ponencia IV Workshop Trabajadores, empresarios y comunidades obreras: conceptos, problemas y escalas de análisis, Rosario, 2016.

Tarcus, Horacio (dir.), Diccionario biográfico de la izquierda argentina, Buenos Aires, Emecé, 2007.

Thompson, Edward P., La Formación de la Clase Obrera en Inglaterra, Barcelona, Crítica, 1989. Vogelmann, Verónica, "Los trabajadores de la carne en el Gran Rosario. Organización gremial y conflictividad laboral (1969-1976)”, Historia Regional 31, Villa Constitución, 2013.

Vogelmann, Verónica, "Conflictividad laboral en épocas de 'resistencia'. Los trabajadores de los frigoríficos rosarinos tras el Golpe de Estado de 1955", ponencia VIII de Sociología de la UNLP, La Plata, 2014.

Williams, Raymond, Marxismo y Literatura, Barcelona, Península, 1980. 


\section{Memorias}

AAVV, Nosotros la Resistencia, Rosario, Junta Promotora de Estudios Históricos y Políticos Martín Fierro, 1998.

Aguirre, Mario, Mario "Negro" Aguirre. Autobiografia. Por el camino de la emancipación, Rosario, Germinal Ediciones, 2009.

Hernández, Amor, Con la marca en el orillo. La memoria de los héroes que no tienen monumento, Rosario, Ediciones del autor, 2015.

Ojeda, Hugo, Quagliaro. La vida de un rosarino en la historia del movimiento obrero, Rosario, Ediciones ATE-Rosario, 2006.

Shapiro, Jaskel, Asalto a la democracia sindical, Rosario, Ediciones Cuaderno, 2015

\section{Hemeroteca}

Compañero, Buenos Aires, 23, 28 de noviembre de 1963 y 36, 4 de marzo de 1964. En www.topoblindado.com

La Tribuna, Rosario, noviembre de 1956; mayo, agosto y septiembre de 1958; enero, febrero y mayo de 1964. En Hemeroteca de la Biblioteca Argentina Juan Álvarez, Rosario.

La Capital, Rosario, mayo de 1958; julio y septiembre de 1962; agosto y septiembre de 1963 y enero y febrero de 1964. En Hemeroteca de la Biblioteca Argentina Juan Álvarez, Rosario

El Litoral, Santa Fe, septiembre de 1958 y febrero de 1964. www.hemerotecadigital.com.ar

Nuestra Palabra, 27 de febrero de 1962. En Hemeroteca y Biblioteca Archivo Cedinci, Buenos Aires.

\section{Documentos}

Fondo particular de Oscar González, disponible en Archivo Gastón Gesrik, Partido Comunista Provincia de Santa Fe:

- Oscar González, Biografía, 10 de setiembre de 1978, Rosario, 13 folios.

- Oscar González, Biografía, 12 de mayo de 1983, Villa Gobernador Gálvez, 8 folios.

- Oscar González, documento s/ref., 2 folios.

- Oscar González, Anécdotas, 1963.

- Oscar González, Cerveceros (biografía), 1964.

- Oscar González, Vida política de Francisco Guarnieri, 22 de agosto de 1989.

- Elecciones CGT Rosario, Voto Lista Blanca, 1963, 1 folio.

Hemeroteca y Biblioteca CEDINCI:

- MUCS, "Declaración del MUCS sobre la unidad y la dirección única del movimiento obrero", Buenos Aires, $1^{\circ}$ de junio de 1960

-MUCS, "Plenario Nacional del MUCS. Informe Central Resoluciones y Organizaciones Representadas", Buenos Aires, 24-25 de junio de 1960

- MUCS, "CGT. Un Congreso de unidad reclama la clase obrera. Posición del MUCS ante el próximo Congreso de la CGT”, Buenos Aires, enero de 1963

\section{Documentos web}


- Programa de La Falda, disponible en http://www.cgtargentinos.org/documentos.htm\#lafalda - Partido Comunista, "El plan de lucha de la CGT. Debe triunfar por la acción unida de la clase obrera y el pueblo. Opinión de los dirigentes y militantes sindicales comunistas", volante, Rosario, 6 de abril de 1964. Disponible en eltopoblindado.com

- MNT Comando La Plata, volante, s/f, disponible en eltopoblindado.com

- MUCS, Para el éxito del Plan de acción de la CGT, ¡luchemos por la unidad sin exclusiones en la central obrera!, volante, Buenos Aires, 5 de agosto de 1964, disponible en eltopoblindado.com

\section{Entrevistas}

-Entrevista a Enrique Gigena, realizada por Verónica Vogelmann, Rosario, mayo 2016. -Entrevista a Leticia Quagliaro, realizada por Silvia Simonassi, Rosario, enero de 2016. 